\title{
EDITORIAL
}

\section{La crisis del euro}

\section{Consejo de Redacción}

Palabras clave: Unión Económica y Monetaria, Unión Europea, euro, crisis financiera y económica, política económica.

Key words: Economic and Monetary Union, European Union, the Euro, the financial and economic crisis, economic policy.

Mots clés: Union économique et monétaire, Union Européenne, euro, crise financière et économique, politique économique.

\section{I. ¿Por qué se habla de la crisis del euro?}

¿Está realmente el euro en crisis? Como piensan algunos ¿hay alternativa al euro?, ¿hubiese sido mejor conservar la soberanía monetaria de los Estados sobre sus propias monedas? $\mathrm{O}$-como piensan otros- ¿los países de la zona euro han resistido mejor la crisis por su mayor estabilidad y la potencia que da una moneda más fuerte que las respectivas monedas nacionales? $\dot{\mathrm{A}}$ quién ha beneficiado el euro? ¿̇a quién beneficia realmente el euro?

Para responder las cuestiones anteriores, en este editorial partimos de algunos conceptos que ya fueron analizados en editoriales anteriores': qué es una unión

' Cfr. "La Moneda Única: ¿̇merece la pena?, ìy después, quée": Revista de Fomento Social 52 (1997) 3-27; reproducido en ROMERO, J.J., editor (2005) Sociedad, política y economía en el cambio de siglo. Reflexiones de "Fomento Social", Santander, Sal Terrae, pp. 233-256. En él se explican las fases para la creación del euro y se realizan algunas preguntas críticas. El editorial se escribió en el momento en 
monetaria y cómo este concepto se aplicó en concreto a la Unión Económica y Monetaria (UEM), así como qué es la política monetaria y la forma en la que ésta se ejecuta en el seno del funcionamiento de la UEM. A partir de estos presupuestos, a continuación abordamos otras cuestiones también importantes: la forma en que la actual crisis económico-financiera ha afectado a la Unión Monetaria, cómo se ha manifestado lo que se ha venido a denominar "crisis de la deuda" y la respuesta a ambas por parte de la Unión Europea (UE) y los gobiernos de los países; dentro de este bloque nos hacemos eco también de los acontecimientos que se han producido recientemente en el seno de la llamada "guerra de divisas". Todo esto nos lleva a plantearnos, a la luz de todo lo expuesto, si realmente la zona del euro (la UEM) es un área monetaria óptima y qué futuro cabe esperar para ella. Finalizamos nuestro texto con unas consideraciones generales que nos llevan a reafirmarnos en las ventajas que proporciona la existencia del euro y la pertenencia de nuestro país a la UEM, a pesar de los inconvenientes que también se presentan; igualmente concluimos que para salir de la debilidad actual del euro hace falta que la UE tenga una política económica común clara y decidida. Si continúan las indecisiones y los retrasos, la UE irá perdiendo importancia en la economía mundial.

\section{Cuestiones previas: recordando conceptos ${ }^{2}$}

\section{I. La Unión Económica y Monetaria europea: concepto}

Una unión monetaria es un proceso por el cual las distintas monedas de un grupo de países se sustituyen por una nueva moneda o por la de uno de ellos. Por lo tanto, por definición desaparecen las monedas de los países que la constituyen y

que la Comisión y el Instituto Monetario Europeo, entre finales de 1997 y 1998, habían de redactar los informes evaluando a los 15 países que formaban parte de de la UE. El editorial comenzaba explicando la lógica de la Unión Monetaria Europea, así como su mecánica, describiendo el proceso de convergencia. A continuación se detenía en el caso español y en el cumplimiento de los criterios de convergencia, para concluir con unos elementos de valoración y unas preguntas. Aquéllos eran (pp. 15-23): ¿ La moneda única es necesaria?, ¿̇qué pros y qué contras tiene la moneda única?, ¿̇cómo valorar la incorporación de España al grupo de cabeza?. En las últimas páginas (23-27) se planteaba la pregunta ¿̇ después de la moneda única, qué? Con diferentes anotaciones críticas sobre el proceso.

2 Un mayor desarrollo del contenido de este epígrafe puede encontrarse en el texto de A. RODERO Franganillo y M. C. López Martín, "La unión y la política monetaria europeas" en P. Caldentey del Pozo y J. J. ROMERO ROdRíGUez (eds.) (2009), El SICA y la UE: la integración regional en una perspectiva comparada, Córdoba, ed. Fundación ETEA para el Desarrollo y la Cooperación. 
por consiguiente dejan de existir sus mercados y sus cotizaciones. En general, se trata de un proceso irreversible; sólo en algún caso puede tener vuelta atrás, sólo alguno de los países que forman la UEM podría plantearse volver a su antigua moneda, aunque sea poco probable. Más bien, hay que ver la unión monetaria como un proceso de unión política y económica, aunque en el caso de la Unión Europea (UE) esta meta parece lejana.

Centrándonos en la Unión Monetaria Europea, podemos recordar que hubo una primera fase que comenzó en 1990 y de alguna manera terminó a principios de 1994. En ella se pretendía concluir la construcción del gran mercado interior, facilitando la libre circulación de capitales, al tiempo que se avanzaba en la convergencia económica. La segunda fase comenzó el 1 de enero de 1994. Estuvo marcada por la aprobación de un tratado, el Tratado de Maastricht (febrero de 1992), que preveía la UEM, es decir, que pretendía preparar el camino para la puesta en circulación de la moneda única. Los mecanismos establecidos para esta segunda fase se orientaron a garantizar la independencia de los bancos centrales, a disciplinar el sector público (eliminando tanto sus déficits como su financiación privilegiada) y a avanzar en la coordinación de las políticas económicas. Los criterios de convergencia, tan de actualidad en aquellos años, no pretendían sino cuantificar lo que se pedía en estos ámbitos. En concreto, en el Tratado de Maastricht se especifica con absoluta claridad que los países que pretendan acceder a la tercera fase tenían que cumplir, durante esta segunda fase, cinco condiciones: los llamados criterios de convergencia nominal.

Estos eran los criterios de convergencia para el acceso a la tercera fase de la UEM:

1. la proporción entre el déficit público y el producto interior bruto no debe sobrepasar el 3\%;

2. la proporción entre la deuda pública y el producto interior bruto no debe rebasar el 60\%;

3. conseguir una estabilidad de precios sostenible y una tasa promedio de inflación (observada durante un período de un año antes del examen) que no excediese en más del 1,5\% la de los tres Estados miembro con mejor comportamiento en materia de estabilidad de precios;

4. el tipo promedio de interés nominal a largo plazo no puede exceder en más de un $2 \%$ el de los tres Estados miembro con mejor comportamiento en materia de estabilidad de precios; 
5. los márgenes normales de fluctuación dispuestos por el mecanismo del tipo de cambio deben observarse, sin tensiones graves, durante por lo menos los dos años anteriores al examen.

En el fondo, estos criterios deben entenderse desde una doble finalidad: antes de la entrada en vigor del euro pretendían servir como barrera de entrada para las economías que pudieran poner en peligro la estabilidad de la nueva moneda; una vez implantada ésta, sirven para garantizar la estabilidad de las economías nacionales incorporadas a la Unión Monetaria. Naturalmente puede discutirse si estos criterios estaban correctamente seleccionados, si las cuantificaciones eran las adecuadas, si el ritmo temporal de su aplicación era el mejor. Pero es indiscutible que cumplían una función, en la medida en que obligaron a los países miembros a mantener una férrea disciplina económica para garantizar la estabilidad. Por otro lado, una vez puesta en marcha la moneda única, los criterios han seguido teniendo una importante función, porque ha habido que respetarlos en el marco del famoso Pacto de Estabilidad, que no es de los menores problemas con que se habrán de enfrentar los países que lleguen a entrar en la moneda única (sobre todo si entran por la "puerta falsa", es decir, sin cumplir estrictamente todos los criterios).

La tercera fase de la UEM se inició el 1 de enero de 1999: su comienzo coincidió con la implantación de la moneda única. El desarrollo de esta fase estuvo previsto con minuciosidad y fue un proceso muy interesante y cargado de implicaciones. Hubo que tomar decisiones muy delicadas. La primera fue, nada menos, determinar en qué países se implantaría desde el primer momento la moneda única (en concreto, fueron once los países que constituyeron inicialmente la UEM: Alemania, Austria, Bélgica, España, Finlandia, Francia, Irlanda, Italia, Holanda, Luxemburgo y Portugal; incorporándose en enero de 2002 Grecia; posteriormente, en 2007 lo hizo Eslovenia, en enero de 2008, Chipre y Malta y, en enero de 2011, Estonia). Luego hubo que fijar las paridades definitivas entre las monedas de los países elegidos. Además hubo que prever una especie de "SME bis" (el Mecanismo de tipo de cambio II -MTC II-) entre el euro y las monedas que se integrarían en un segundo momento. Al mismo tiempo hubo que avanzar en el desarrollo del Banco Central Europeo que se constituiría en 1998. Por fin, hubo que proceder a sustituir las monedas nacionales por el euro, proceso que se realizó a partir de enero del año 2002.

De todos los complejos aspectos que incluía la tercera fase, hay al menos dos sobre los que conviene detenerse, aunque sea con brevedad. El primero de ellos es el Sistema Europeo de Bancos Centrales (SEBC) y el Banco Central Europeo (BCE). 
Éste último es el encargado de emitir el euro (tiene la exclusiva en la emisión de moneda). El SEBC (formado por el BCE y el conjunto de todos los bancos centrales nacionales, incluidos los de los países que no estén dentro de la moneda única) diseña la política monetaria de la Unión Europea, una política que afecta directamente ante todo a los países "in" (los miembros de la eurozona; naturalmente, los países "out" mantienen sus propias monedas y desde luego sus propios bancos centrales independientes).

La segunda cuestión a destacar en esta tercera fase era la fijación definitiva de las paridades de las monedas que serían sustituidas por el euro. Podía preverse que habría negociaciones muy intensas; incluso podría ocurrir que se produjera un retraso o hasta el fracaso del euro debido precisamente a esta cuestión de paridades. Era fácil que los gobiernos quisieran aprovechar esta última oportunidad que se les presentaba para forzar una cierta devaluación competitiva que estimulase las exportaciones abaratándolas y frenase las importaciones, aunque sólo inicialmente. Había que exigir el máximo rigor, de manera que las paridades que se fijasen correspondieran al poder de compra de las diferentes monedas, pero también a los demás datos económicos de cada país. El principio era bastante claro, pero la puesta en práctica era, sin embargo, compleja. Y más aún, si se tiene en cuenta que los mercados financieros también querían tomar cartas en el asunto. Finalmente, en diciembre de 1998, el Consejo de Ministros de la UE fijó los tipos irrevocables de conversión de las distintas monedas con relación al euro.

\subsection{La política monetaria única}

La política monetaria puede definirse como el proceso continuado de control de las variables monetarias con el fin de alcanzar determinados objetivos económicos. Su establecimiento requiere la selección de la variable estratégica instrumental para alcanzar un objetivo monetario concreto (en términos de precios, renta, empleo, etc.), que debe ser susceptible de control con un cierto grado de seguridad, y mostrar una alta correlación con el objetivo monetario final. Con respecto a dicho objetivo, la elección teórica se encuentra entre la oferta monetaria y el tipo de interés; es decir la variable cuantitativa o el precio.

Si bien el objetivo final de la política monetaria es la estabilidad de precios, es conocido que existen retardos en la transmisión de los efectos de las variaciones en las variables controladas por la autoridad monetaria sobre las variables finales en las que se desea influir. Por esta razón, un elemento fundamental que determina el esquema mediante el que se ejecuta la política monetaria, es la existencia de una 
variable sobre la que se establecen objetivos precisos $y$, en concreto, la disyuntiva que se llegó a plantear en el seno del IME era si dicha variable debía ser directamente una de las variables finales (en este caso, los niveles de precios) o una variable intermedia en el mecanismo de transmisión de los impulsos monetarios (alguna medida de la cantidad de dinero -un agregado monetario-) . La decisión final sobre una de las dos estrategias planteadas se dejó al BCE ly no fue tomada por el IME); su Consejo de gobierno en octubre y diciembre de 1998 hizo públicos los principales elementos de su estrategia de política monetaria y estableció una combinación de las dos estrategias. La políica monetaria está orientada hacia la estabilidad y se basa en tres elementos fundamentales : una definición cuantitativa del objetivo prioritario (la estabilidad de precios ) y dos pilares para alcanzar dicho objetivo: un papel destacado para el dinero (que se manifiesta en el anuncio de un valor de referencia cuantitativo de la tasa de crecimiento de un agregado monetario amplio) y una evaluación de las previsiones del comportamiento de los precios a través de la información proporcionada por un conjunto amplio de indicadores.

\subsection{El funcionamiento de la UEM: la cotización del euro y la ejecución de la} política monetaria

El euro sigue un sistema de flotación libre con relación al dólar, la libra esterlina etc. Ello no impide que puedan realizarse algunas intervenciones en los mercados, para influir, en alguna medida, sobre su cotización. Existe un número elevado de países que vinculan su moneda al euro o emplean el euro como moneda propia (San Marino, Vaticano, Mónaco, Andorra, Kosovo, Montenegro, Benín, Costa de Marfil, Congo, Comores, etc.). Diariamente, el BCE publica la cotización del euro con relación a 37 monedas (a las 2,25 pm.), obtenidas a partir de la información proporcionada por los bancos centrales y de otras instituciones financieras. Se trata de una cotización inversa, en la que el euro se toma como unidad.

Si observáramos la evolución de la cotización del euro respecto al dólar y a las principales monedas -yen y libra-, podríamos apreciar que la moneda europea se fortaleció a lo largo del período 2001-2007, por lo que una primera cuestión a plantearnos sería acerca de las causas que explican este comportamiento. Al respecto, conviene recordar que el dólar USA ha tenido un papel peculiar en los mercados internacionales: a) es la principal moneda de reserva ${ }^{3}$; y b) mercados

\footnotetext{
${ }^{3}$ Existe un elemento de confianza en esta moneda que provoca que, en determinadas circunstancias y en algunos países, circulen indistintamente la moneda nacional y el dólar, lo que sin duda refuerza el papel central del dólar en la economía internacional.
} 
importantes de materias primas (crudos petrolíferos, etc.) utilizan el dólar como moneda de cambio.

Estas características permiten que el déficit exterior de Estados Unidos (EEUU) se pueda financiar sin problemas a través de las entradas de capitales de otros países. Precisamente esto ha permitido la situación muy deficitaria de la balanza comercial de Estados Unidos en los últimos años. Sin embargo, el crecimiento del déficit terminó por afectar negativamente a la cotización de la moneda americana. De aquí que se pueda afirmar que la subida de euro fue una consecuencia de la bajada del dólar; dado que algunos países, especialmente China, impidieron un ajuste de sus monedas, la carga del equilibrio en los mercados de divisas recayó en el euro y en alguna otra divisa, tal como la libra esterlina. En todo caso, una situación más equilibrada del dólar y del euro exigía una reducción del déficit estadounidense, lo que requería una mayor disciplina de su economía (recordemos también el elevado déficit público existente); no bastó con las variaciones que se venían experimentando en los mercados de divisas para reducir el desequilibrio de las cuentas exteriores de EEUU.

Una segunda causa de la subida del euro hasta el año 2007 fue la diferencia a favor de la eurozona de los tipos de interés en estos dos grandes espacios. Esto no fue, sin embargo, la causa principal, como lo demuestra que el acercamiento de las tasas de interés oficiales del BCE y de la Reserva Federal a finales de 2004 no determinó de forma inmediata un freno a la elevación del precio del euro. Posteriormente se observaron algunos cambios de las cotizaciones que probablemente fueron ocasionados por la variación de los tipos de interés, por lo que podemos decir que la relación no se manifestó de forma clara en todos los casos.

Los principales efectos de este comportamiento del euro se podrían sintetizar en las siguientes ideas:

- Fue una muestra de su fortaleza; ello no fue un simple fenómeno "social" o "psicológico" ya que también tuvo consecuencias prácticas: a) incorporación del euro a las reservas exteriores (recuérdese la política de Rusia y algunos de los países de la OPEP en esta línea); b) utilización como instrumento de cambio en algunos países europeos e incluso latinoamericanos.

- Perjudicó las exportaciones de la eurozona a terceros países; efectivamente, en el período comentado empezaron a aparecer estos efectos negativos en las ventas exteriores de los países del euro. 
- Abarató las importaciones de terceros países; en este sentido, la subida de los precios de los crudos fue menos gravosa para la eurozona.

- Como consecuencia de los aspectos comentados en los dos puntos anteriores, se produjo un efecto antiinflacionista, lo que permitió que la política monetaria del BCE fuese menos restrictiva.

Centrándonos ahora justamente en la ejecución de la política monetaria por el BCE debemos indicar que ésta, a pesar de su complejidad, descansa sobre todo en las decisiones adoptadas semanalmente sobre el tipo de interés de las denominadas operaciones principales de financiación, que son las que determinan el "tono" que el BCE va a adoptar, en el sentido de aplicar una política más restrictiva (subida de tipos) o de carácter más "relajado" (reducciones de tasas de interés). Por lo tanto, una forma de evaluar las actuaciones realizadas en estos últimos años es observar la evolución de estos tipos de interés en relación con el objetivo principal del BCE (la estabilidad de precios).

Durante los años previos a la crisis económica financiera, en sus primeros meses de funcionamiento, el BCE siguió una política monetaria de reducción del tipo de interés y luego de mantenimiento (hasta octubre de 1999). Después mantuvo una política restrictiva hasta abril de 2001, llegando el tipo de interés hasta el 4,75\%. Estos meses se caracterizaron por una tendencia alcista en los precios y una cierta expansión de la actividad económica, la cual comenzó a moderarse en el verano de dicho año. A partir de entonces, la desaceleración económica se hizo especialmente intensa, al tiempo que las variaciones de los índices de precios se moderaban. Esto determinó que el BCE redujese el tipo de interés de las operaciones principales de financiación hasta situarlo en el $2 \%$ que se mantuvo hasta 2006 . El crecimiento del Índice Armonizado de Precios de Consumo (IAPC) determinó sucesivas elevaciones del tipo de interés hasta alcanzar el $4 \%$ en junio de 2007 . Ante las turbulencias de los mercados financieros, iniciadas en dicho año, el BCE mantuvo invariable la tasa de interés para "tranquilizar" los mercados hasta que, presionado por la inflación, el BCE elevó dicha tasa al 4,25\% en julio de 2008.

Hecha esta descripción general de la evolución de los precios y de los tipos de interés de la autoridad monetaria europea, cabría hacer una valoración de las decisiones adoptadas. Así, puede afirmarse que la política monetaria del Banco Central Europeo mantuvo claramente como objetivo prácticamente único la estabilidad de los precios, adaptándose por tanto a la definición establecida por la Unión Europea. Sólo en aquellos momentos en que la estabilidad estaba plenamente asegurada se atendió otro objetivo: el crecimiento de la actividad económica. Otras variables fueron aspectos 
a considerar que completaron la información, pero que no afectaron claramente a las decisiones del BCE: así, por ejemplo, el comportamiento de la economía real y sus expectativas fueron valoradas como elementos de estabilidad o inestabilidad de los precios, mientras que la cotización del euro no determinó en ningún momento una política de intervención del BCE, si bien su debilidad o fortaleza preocupó al Banco, por sus efectos sobre la estabilidad de precios en general.

A pesar de lo que se acaba de indicar, la evolución descrita más arriba y los datos relativos a las tasas de variación del IAPC, que llegaron a superar en algunos casos el valor del tipo de interés de referencia, muestran que en los primeros meses de actividad del $\mathrm{BCE}$, éste ejerció una actividad más intensa en el manejo de esta variable con el fin de enviar señales claras al mercado acerca de cuál era su forma de desempeñar la función que tenía encomendada. Más adelante, a partir de septiembre de 2001, se aprecia que la frecuencia en la toma de decisiones de modificación de los tipos de interés disminuyó, lo que podría ser indicativo de que, una vez "asentado" en su papel, existieron otros elementos que condicionaron, en cierta medida, la toma de decisiones por parte del $\mathrm{BCE}$; igualmente, parece que se fueron realizando también las operaciones manejando en mayor medida las cantidades de recursos concedidas a las instituciones en función de la situación en cada momento, evitando de esta forma las variaciones de los tipos de interés oficiales. En este último sentido, hay que tener en cuenta la situación de la actividad económica en algunos de los países más fuertes dentro de la UEM y las presiones existentes desde ciertos gobiernos de la UE, las decisiones adoptadas desde otros ámbitos (como la Reserva Federal), etc.

\section{El período 2007-20 I0: la crisis económico-financiera y sus secuelas}

\section{I. Efectos de la crisis financiera sobre la Unión Monetaria}

Las causas y los efectos de la crisis de la economía mundial que se inició en 2007 son muy conocidos por lo que no entraremos en detalles sobre los que se ha debatido repetidamente. Nos interesa, sin embargo, aludir al problema en relación con la Unión Europea (UE) y en especial con el área del euro; como es lógico, los efectos son en gran medida idénticos a los que ha experimentado el resto del mundo.

Desde un punto de vista real, los resultados en Europa fueron más lentos de lo que se esperaba, pero fueron más profundos de los que se temía: recesión de 
todas las economías europeas, elevados niveles de paro, "estallido" de la burbuja inmobiliaria etc.

Aunque subrayamos que la crisis tuvo un componente real, los problemas financieros tuvieron también una relevancia que no se puede ignorar. Igual que sucedió en Estados Unidos (USA), importantes bancos europeos tuvieron problemas que obligaron a los gobiernos a acudir en su auxilio; la caída del valor de algunos activos (relacionados con las pérdidas sufridas por algunos fondos de inversión, falta de liquidez de estos, etc.) y el fuerte incremento de la morosidad, sobre todo de los créditos hipotecarios, explican en gran parte la quiebra, o el riesgo de quiebra, de entidades bancarias.

El desconocimiento del valor real de muchos activos financieros y la contaminación de los balances bancarios, creó una desconfianza generalizada que llevó a los mercados financieros, sobre todo al interbancario, a una congelación de sus operaciones. En consecuencia, casi toda la banca europea tuvo problemas de liquidez, ya que los mercados financieros se cerraron para ellos.

Veamos a continuación los efectos de la crisis sobre los principales temas tratados en este editorial. Distinguiremos dos etapas: $1^{\circ}$ el inicio de las turbulencias hasta 2008; y $2^{\circ}$ la profundización de la crisis durante el bienio 2009-2010.

$1^{\circ}$ La crisis de liquidez que se produjo en agosto de 2007, llevó al BCE a realizar fuertes inyecciones de liquidez al sistema para aliviar las tensiones de los mercados interbancarios. Efectivamente, la intervención del BCE en los mercados, en diciembre de 2007, presionó a la baja el elevado nivel de los tipos de interés en el mercado interbancario. Idéntica política siguió la Reserva Federal de USA y el Banco de Inglaterra., aunque de forma menos intensa que el BCE.

Hay que tener en cuenta que el BCE venía elevando los tipos oficiales anteriormente, para frenar presiones inflacionistas. La política indicada en el párrafo anterior fue unida a un mantenimiento de los tipos de interés oficiales, interrumpiendo las subidas que estaban previstas. El BCE estaba siguiendo una política muy prudente dada la situación de crisis aunque sin abandonar su objetivo fundamental: el freno de la inflación.

Por otra parte, los sucesos que produjeron la crisis manifestaron una actuación permisiva de los organismos reguladores; en este sentido el BCE carece de competencias ya que cada país de la UEM tiene su propio regulador, por lo que el banco europeo no actuó en este sentido. 
$2^{\circ}$ Desde el 2008, la economía de la mayor parte de los países, especialmente del mundo "desarrollado", han sufrido una recesión que ha empezado a superarse en 2010, pero la salida es lenta y débil cuantitativamente, lo que ha impedido la normalización de los mercados de trabajo, permaneciendo unos altos niveles de paro e incluso una elevación de éstos en los casos de USA y gran parte de la UE. Para que la recesión no se transformase en una depresión, los gobiernos de estas dos áreas económicas pusieron en marcha unas políiticas expansivas de carácter fiscal principalmente; ello unido a unos déficits cíclicos de los presupuestos llevó a unas cifras negativas muy importantes del sector público; sobre ello volveremos en el apartado siguiente.

Como hemos indicado, el BCE tiene un solo objetivo: la política antiinflacionista; durante estos años los riesgos de inflación eran casi nulos, por lo que al principio, el BCE se limitó a una política acomodaticia bajando gradualmente las tasas oficiales de interés hasta llegar al 1\%, muy cercano al tipo establecido por la Reserva Federal (cerca del 0\%). Dada la lentitud de la recuperación del PIB y de los mercados financieros, el BCE inició una política monetaria "heterodoxa", auténtica novedad en el contexto de las actuaciones del banco europeo.

La política del BCE ha incluido las siguientes actividades que ordenamos cronológicamente:

1) El descenso del tipo de interés ya indicado.

2) Importantes inyecciones de liquidez al sistema para permitir su normalización.

3) Ampliación de los tipos de valores que aceptaría como colaterales, incluyendo títulos con un "rating" muy bajo; esto es lo que se ha conocido coloquialmente como "barra libre".

El resultado de todo esto, ha sido una cifra, nunca vista, de préstamos del BCE al sistema, que alcanzó unos 442.000 millones de euros en el verano de 2009. Como hemos subrayado esta política pretendía principalmente la normalización de los mercados interbancarios, lo que se consiguió en ciertos momentos pero no de forma continuada; la crisis de la deuda que trataremos en el apartado siguiente "cerró" de nuevo estos mercados.

Ahora se ha conseguido una situación algo más "relajada" por las siguientes razones: 
1) el BCE ha ofrecido recursos para que al vencimiento de algunos préstamos al sistema, éstos fueran sustituidos por nuevas operaciones;

2) algunas grandes entidades financieras, sobre todo españolas, han utilizado las cámaras de contrapartida europeas para conseguir recursos, aunque sea con un coste más alto.

El BCE ha fijado el inicio de 2011 para contener la "barra libre", reduciendo la proporción de recursos que se pueden conseguir con la garantía de valores de bajo "rating". Dada las sucesivas crisis de los países de la UE, y en concreto del área del euro, esta decisión hay que considerarla como una simple propuesta. Ya veremos...

Otra actuación del BCE ha sido la colaboración con el Comité de Supervisores Bancarios Europeos para realizar unas pruebas de resistencia de las entidades bancarias de la UE (los llamados "stress tests"); los resultados han sido satisfactorios en general, y especialmente en el caso español, lo que ha permitido una reducción de la incertidumbre que ha llevado, también, a esa relativa normalización de los mercados financieros a la que hemos aludido.

Un aspecto negativo de las entidades bancarias europeas y sobre todo de las españolas es el continuo incremento de la morosidad; mientras continúe este proceso la normalidad de los mercados de capitales y de crédito no se podrá alcanzar, dificultando la recuperación del crédito a las empresas, sobre todo de las pymes, y a los consumidores. No olvidemos que los problemas del interbancario no sólo afectan a la oferta de recursos sino también a su precio, así, por ejemplo, el Euribor a doce meses ha alcanzado en octubre de 2010 un nivel que no se había visto desde julio de 2009, es decir en el momento en que la crisis se agudizó. Pero en la solución de estos problemas poco puede hacer el BCE, al menos de forma directa.

No podemos finalizar este apartado sin hacer una referencia al comportamiento de las bolsas, no solamente porque son uno de los principales mercados de inversión, sino también porque las cotizaciones bursátiles son un buen indicador de cómo va la economía.

Distinguiremos los dos periodos citados anteriormente (2007-2008 y 2009-2010): 
1) dado que los problemas se iniciaron a mediados de 2007, este año presentó un balance positivo de las bolsas. En 2008, con unas economías en "caída libre", las bolsas sufrieron un grave quebranto como era de esperar;

2) en 2009 , las bolsas subieron moderadamente porque se esperaba una próxima recuperación y normalización de los mercados. Puesto que el comportamiento de estos ha sido lento y lleno de incertidumbre, el año 2010 ha vuelto a presentar una caída bursátil.

Todo este cuatrienio ha estado marcado por lo tanto por una alta volatilidad (y un descenso del volumen de negocios) de los mercados bursátiles. Así por ejemplo, la crisis de la deuda que se comenta más adelante, determinó un primer semestre de 2010 muy negativo en las bolsas; el segundo semestre, en el que los problemas de deuda se han suavizado, ha presentado una recuperación parcial de la caída de los primeros seis meses. Otro ejemplo, el anuncio de que se iban a elaborar las pruebas de resistencia deprimió inicialmente los precios bursátiles, pero conforme se fue conociendo que los "tests" serían positivos, las cotizaciones fueron "descontando" estos datos, que finalmente dieron lugar a una mejora de las bolsas. Un tercer aspecto a considerar son las actuales turbulencias en los mercados de divisas; hasta ahora las economías que han experimentado una depreciación de sus monedas han mejorado el nivel de la bolsa, si bien más que un cambio global la subida se ha centrado en las cotizaciones de las compañías exportadoras; por otra parte este proceso ha llevado a muchos inversores a cubrir los posibles cambios de cotización de las monedas; una nueva presión sobre los mercados.

Un último dato sobre la anormalidad del comportamiento de los mercados financieros: siempre se ha argumentado que los mercados de renta fija y de renta variable se comportan de forma opuesta: cuando bajan los precios de los bonos sube la bolsa y viceversa. En el tercer trimestre de 2010, aparece una subida de los precios de ambos mercados simultáneamente. La explicación no es sencilla, los bajos tipos de interés determinan una deuda pública con bajos rendimientos en los países más poderosos (como es sabido unas rentas más bajas de los bonos quiere decir unos precios más altos de la deuda); mientras la bolsa sube porque los resultados de las grandes empresas han crecido a pesar de la debilidad de la economía de muchos países.

Tenemos también que tratar el otro tema central de este editorial: el comportamiento del euro, pero como ello va unido a los problemas recientes de los mercados de divisas, lo veremos en otro apartado. 


\subsection{La crisis de la deuda}

Durante este año 2010, un nuevo problema se ha añadido a los efectos que ha provocado la crisis económico-financiera que se inició en 2007: un episodio de crisis de deuda soberana que ha afectado a algunos de los países de la periferia geográfica de la Unión Europea: Grecia, Irlanda, Portugal, España... Esta crisis tiene su causa última en el elevado y rápido incremento de los déficits públicos y de las emisiones de deuda pública destinadas a financiar políticas de gasto emprendidas por los gobiernos como respuesta a la crisis. De hecho, el deterioro de las finanzas públicas comenzó en 2008 y se intensificó en 2009, teniendo un carácter generalizado en casi todos los países de la zona euro. Sin embargo, también con carácter generalizado, los planes de corrección se han ido aplazando para los próximos años y, en muchos casos, no se habían detallado medidas a corto plazo para su corrección.

No obstante, estas circunstancias que, como indicamos, han sido casi generalizadas en todos los países de la eurozona, han dado lugar, en los casos concretos citados, a una situación de tensión y turbulencias en los mercados de deuda. Así, desde comienzos de 2010, los diferenciales entre la deuda pública a diez años de algunos países europeos y los bonos alemanes comenzaron a aumentar, principalmente debido a la creciente inquietud observada en los mercados respecto a la sostenibilidad de las finanzas públicas, como se ponía de manifiesto en el incremento de la deuda y de los déficits presupuestarios. La inquietud llegó a tal punto que algunos mercados secundarios se paralizaron.

Probablemente, la gravedad del problema en los países afectados no estribaba sólo en la magnitud y la rapidez con la que ha aumentado el volumen de su deuda pública, sino en que, además, ésta ha sido colocada en buena medida a inversores extranjeros y entidades financieras que, ante un elevado deterioro de las cuentas públicas y unas perspectivas económicas y presupuestarias poco favorables, se muestran reacios a prestar nueva financiación. En el fondo, pues, se trata de un problema de credibilidad acerca de las políticas a acometer por parte de ciertos gobiernos y de una mayor debilidad relativa de las finanzas públicas en determinados casos. Por ejemplo, en el caso de Grecia, la magnitud del déficit y del saldo de la deuda en circulación eran ciertamente elevados, pero hay que recordar que este país previamente había falseado sus cuentas públicas, de manera que finalmente se vio obligado a reconocer un inesperado y enorme déficit público (alrededor del 13\% del PIB) que llevaba a que la deuda pública superase el $120 \%$ del PIB. Esta carga se vio agravada por la desconfianza de los mercados financieros, que obligaron al gobierno griego a pagar una elevada prima para 
financiarse. Finalmente, tras muchas vacilaciones, el gobierno griego puso en marcha una serie de medidas de ajuste dirigidas a sanear sus cuentas.

Sin llegar al extremo griego, en general, debemos tener en cuenta que en las circunstancias de dificultades en las cuentas públicas, la necesidad de nuevos recursos para poder atender los compromisos existentes (relacionados con los vencimientos de deuda previstos, los pagos por intereses y los gastos corrientes) resulta aún más complicada: los fondos necesarios deben conseguirse en unos mercados en los que los inversores son reacios a asumir mayores riesgos, lo que implica un fuerte incremento de las primas de riesgo exigidas en las nuevas emisiones de deuda pública; además, se produce una "huida" de los emisores más arriesgados, lo que eleva extraordinariamente la volatilidad del mercado secundario y reduce su liquidez.

Estas circunstancias se han visto acentuadas, además, por las rebajas que las agencias de "rating" han efectuado en las calificaciones otorgadas a los valores de renta fija de algunos de los países indicados. A este respecto, debemos recordar que, concretamente en el caso de España, la rebaja de un escalón que la agencia Standard \& Poors realizó en el mes de mayo, ha podido suponer un fuerte aumento en el pago de intereses de la deuda ya que en las emisiones que se han realizado a partir del momento en que la rebaja se hizo pública han debido remunerar a los inversores con un tipo de interés superior al existente antes de dicho anuncio, al haber aumentado el riesgo de impago ${ }^{4}$. No obstante, no todos los países se encuentran en idénticas circunstancias: mientras que los bonos emitidos por el estado griego tienen una calificación similar a la de los denominados "bonos basura", la deuda española se situaba en dicho mes en la misma calificación que Japón y por encima de Italia.

Más recientemente, el estallido de un nuevo episodio de crisis en los mercados de deuda ha afectado a los países denominados periféricos, aumentando los diferenciales de los tipos de interés de la deuda pública de estas economías frente al bono alemán a 10 años (considerado como la referencia). Este proceso ha alcanzado con mayor virulencia en este caso a Irlanda, pues en este país, además de los problemas presupuestarios existentes en otros países (el déficit público se sitúa en el $32 \%$ del PIB), el sistema bancario pasa por graves dificultades. En consecuencia, la situación ha dado lugar a nuevos anuncios de políticas de ajuste: el Gobierno ha anunciado un ajuste de 6.000 millones de euros en el próximo presupuesto, lo que supone

${ }^{4}$ Además, este aumento de la prima de riesgo ha penalizado también a las empresas españolas, que tienen que soportar unos intereses más elevados en sus emisiones. 
una cifra muy elevada si se tiene en cuenta que Irlanda tiene unos 4,5 millones de habitantes y su economía genera un PIB de 160.000 millones de euros.

\subsection{Nuevas decisiones de política económica de la UE y de algunos países miembros}

La crisis económica y financiera ha provocado que dentro de la UEM, al igual que en otros ámbitos (UE, G-20, etc.) deban llevarse a cabo medidas de distinto signo, tanto de manera individual en cada país, como desde un ámbito más centralizado para el conjunto del área. Respecto a éstas últimas, ya hemos mencionado anteriormente las actuaciones llevadas a cabo por el BCE en el seno de la ejecución de la política monetaria, por lo que no volveremos sobre ellas.

La crisis de la deuda griega primero, y el contagio hacia otros emisores soberanos después, obligaron también a los Gobiernos de la zona a anunciar, en mayo de este año 2010, un conjunto integral de medidas, que en definitiva vienen a reconsiderar los mecanismos de coordinación y de coacción mutuos dentro de la eurozona. La creación de un fondo de rescate (la denominada Facilidad Europea de Estabilidad Financiera) para actuar en caso de emergencia ha sido el paso más significativo. En esencia, este mecanismo consta de una facilidad de préstamo de la UE a disposición de todos los Estados miembros por un importe de hasta $60 \mathrm{~mm}$ de euros, así como de un acuerdo intergubernamental para proporcionar ayuda financiera por importe de hasta $440 \mathrm{~mm}$ de euros durante un período de tres años a través de una entidad de propósito especial, garantizado de forma prorrateada por los Estados miembros que participen en la facilidad. La canciller alemana propuso que las entidades acreedoras (bancos, etc.) soportasen también las pérdidas sufridas por algún país que tuviera que utilizar esta "Facilidad". La alarma consiguiente de los mercados financieros ha obligado a dejar esta propuesta, de momento, en el "congelador".

El FMl participará en acuerdos de financiación y se espera que proporcione asistencia equivalente al menos a la mitad de la contribución realizada por la UE a través de sus mecanismos habituales. Paralelamente a este acuerdo, por parte del BCE la medida adoptada fue el Programa para los Mercados de Valores, en cuyo marco el BCE puede realizar intervenciones en los mercados secundarios de deuda pública y privada de la zona del euro para garantizar la profundidad y la liquidez en los segmentos del mercado con un comportamiento disfuncional y restablecer el adecuado funcionamiento del mecanismo de transmisión de la política monetaria. 
Otro de los temas sobre los que se ha trabajado en el seno de la UE está relacionado con la supervisión de las entidades financieras. No cabe duda de que la crisis financiera ha puesto de manifiesto la envergadura de las posibles repercusiones derivadas de la quiebra de grandes instituciones financieras, así como la fragilidad del sistema financiero ante determinadas características de las instituciones y los mercados. No está de más recordar, además, como determinados acontecimientos relacionados con las entidades y los mercados se han multiplicado, alcanzando sus consecuencias una mayor dimensión por la espiral negativa de reacciones adversas entre el sistema financiero y la economía real. Estas circunstancias explican que la UE aprobara en septiembre un nuevo sistema de supervisión financiera que busca detectar a tiempo los riesgos que amenacen la estabilidad y evitar la aparición de nuevas crisis en alguna de las entidades bancarias claves.

La nueva estructura de supervisión tendrá dos ámbitos: uno de carácter global y otra más microeconómico. La responsabilidad del primero recaerá sobre el denominado comité europeo de riesgo sistémico, que estará dirigido por el presidente del Banco Central Europeo (BCE) y del que formarán parte los gobernadores de los bancos centrales nacionales. Además, existirán tres nuevas autoridades europeas de supervisión (banca, seguros y mercado de valores) que sustituirán a los comités consultivos existentes hasta ahora y dispondrán de poderes vinculantes para poder solventar disputas entre supervisores nacionales, dar instrucciones directas a una entidad en crisis y prohibir productos financieros de riesgo si fuera necesario. Por lo tanto, se responsabilizarán, en colaboración con los correspondientes supervisores nacionales, de asegurar la solidez y solvencia de las respectivas entidades en cada uno de los sectores. ${ }^{5}$

Respecto a los gobiernos europeos, en la declaración de los jefes de Estado o de Gobierno de la zona del euro del 7 de mayo de 2010, estos se comprometieron a garantizar la estabilidad, unidad e integridad de la zona y acordaron adoptar todas las medidas que fuesen necesarias para cumplir sus objetivos presupuestarios de acuerdo con las recomendaciones formuladas en el marco de los procedimientos aplicables en caso de déficit excesivo. En cuanto a los gobiernos de los países más afectados, también se han visto obligados a aplicar medidas presupuestarias drásticas que garanticen el retorno a unos déficits públicos aceptables y que frenen

\footnotetext{
${ }^{5}$ Las tres autoridades europeas desarrollarán nuevos estándares técnicos y recomendaciones, establecerán normas específicas para los supervisores nacionales y las entidades financieras, y supervisarán la correcta aplicación de las normativas. En caso de crisis, podrán imponer medidas correctivas concretas a las entidades afectadas y prohibir algunas operaciones o productos financieros tóxicos si fuera necesario. También actuarán de árbitros en el caso de desacuerdo entre dos supervisores nacionales en el control de una entidad transnacional.
} 
la espiral de la deuda. Así, los Gobiernos de España, Italia y Portugal presentaron medidas de saneamiento adicionales, aparte de las especificadas en las respectivas actualizaciones de los programas de estabilidad publicadas a principios del año 2010. Básicamente, las medidas presentadas consistieron en lo siguiente:

- En España, el plan de austeridad fiscal del Gobierno incluye recortes de los salarios públicos en 2010 y congelación en 2011 , congelación de las pensiones en 2011 , supresión de beneficios fiscales para las familias jóvenes y reducciones de la inversión pública y de otras partidas del gasto, con un impacto total acumulado que ascenderá al $0,5 \%$ y al $1,5 \%$ del PIB en 2010 y 2011 , respectivamente. De esta forma, los objetivos del Gobierno español en relación con el déficit son el $9,3 \%$ del PIB para 2010 y el $6 \%$ del PIB para 2011 (frente al $9,8 \%$ y el $7,5 \%$, respectivamente, que figuran en el programa de estabilidad).

- Las medidas adoptadas por el Gobierno italiano se centran principalmente en el gasto y afectan, en particular, a los salarios públicos, al gasto en pensiones, a las transferencias a las administraciones locales y a los consumos intermedios. También se adoptarán algunas medidas correctivas por el lado de los ingresos, concretamente para luchar contra el fraude fiscal.

- Por su parte, las medidas adicionales de saneamiento que se anunciaron en Portugal incluyen subidas de los impuestos directos e indirectos, así como reducciones o aplazamientos del gasto público y la aplicación anticipada de medidas de saneamiento previstas.

En conjunto, como se puede apreciar, se pueden calificar de medidas que presentan el riesgo de frenar el crecimiento económico pero que son imprescindibles para que las desmesuradas primas de riesgo que deben pagar estos gobiernos para seguir obteniendo fondos vuelvan a niveles sostenibles. En definitiva, el ajuste interior es la única alternativa puesto que, de no llevarse a cabo, el alza de la prima de riesgo y la falta de financiación exterior conducirían a una situación de práctico estancamiento económico cuando no a una vuelta a la recesión.

\subsection{La guerra de las divisas}

Sobre el comportamiento de los mercados de divisas, y en concreto del euro, conviene también distinguir dos etapas durante la crisis, igual que hemos hecho en algún apartado anterior: $2007-2008$ y $2009-2010.6$

${ }^{6}$ Recordemos que, como ya hemos indicado, antes de la crisis, el dólar estaba perdiendo importancia 
En el primero de los bienios indicados, los efectos de la crisis sobre los mercados de divisas fueron: la continuación del proceso de depreciación del dólar y el reforzamiento de la cotización del euro. Además de la apreciación de la moneda europea, se elevó la cotización de la libra esterlina y de algunas otras monedas que tienen una menor importancia en los mercados de divisas. Este comportamiento favoreció las exportaciones USA y frenó sus importaciones; de esta forma se redujo el déficit exterior de Estados Unidos, aunque siguió siendo elevado. El yuan chino presentó pocas variaciones respecto al dólar, lo que llevó a un elevado superávit del país asiático, el cual, además de un fuerte crecimiento de sus reservas, realizó importantes inversiones financieras que animaron la especulación, siendo este comportamiento una de las causas de la crisis financiera. En el área del euro los efectos fueron los contrarios: mayor dificultad para las exportaciones y abaratamiento de las importaciones, lo cual afectó negativamente al saldo exterior, si bien tuvo un efecto positivo sobre la eurozona: una menor presión inflacionista. La subida del euro a pesar de las presiones del mercado hizo pensar que la moneda europea era una divisa sólida y que el proceso iniciado en los años noventa se estaba consolidando; el hecho de que la crisis no impidiera la incorporación de nuevos miembros a la UEM confirmó esta opinión.

Sin embargo, a final del bienio se produjo un cambio importante: el dólar se fue apreciando progresivamente y el euro se depreció al mismo tiempo. ¿¿Qué había pasado? Las causas no son muy claras, pero se pueden apuntar algunas razones: quizás, según las expectativas más generalizadas se esperaba que la recuperación de USA sería previa a la europea; quizás, la recesión en Europa, más profunda de lo que se temía inicialmente afectó negativamente al euro; quizás, la igualación de las tasas oficiales de los bancos centrales eliminó la ventaja que ofrecía el euro a los inversores; quizás, las compras masivas de dólares por algunos fondos de inversión (los llamados "hedge funds") para reducir su endeudamiento presionó la cotización de la moneda americana. En todo caso, la lógica de los mercados demostró que en momentos de convulsión económica, el dólar seguía siendo la moneda refugio, por lo que el proceso de su posible sustitución por el euro no había sido más que un espejismo.

El bienio 2009-2010 no ha estado exento de una fuerte volatilidad de los mercados de divisas lo que ha generado variaciones de distinto signo de las cotizaciones de las monedas y en concreto del euro.

como moneda de reserva mientras que el euro le iba sustituyendo en parte, aunque también se consolidaron como activo refugio el oro y algunas otras materias primas. 
En 2009, tras un corto periodo de depreciación del euro frente al dólar, continuación del proceso que se ha comentado en el punto anterior, en el resto del año (unos nueve meses) el euro se apreció sensiblemente; los datos negativos de la economía americana y la política económica de su gobierno, podrían explicar, en parte, este comportamiento. En 2010, sin embargo, la crisis de la deuda que afectó a varios países europeos llevó a una depreciación del euro que se extendió hasta mitad del año. A partir de julio se observó un nuevo cambio: el euro se apreció frente al dólar pero también en relación con otras divisas. Como ya hemos comentado anteriormente podríamos plantearnos si es correcto afirmar que el euro sube o si más bien debemos subrayar que lo que sucede es que el dólar baja.

Veamos algunos aspectos relacionados con los cambios de las cotizaciones:

- USA mantiene una política expansiva mientras que la UE se ha centrado en la consolidación fiscal; ello debería llevar a un dólar débil y a un euro fuerte, una vez superada la crisis de la deuda.

- Algunos países han tratado de debilitar su moneda para conseguir un incremento de sus exportaciones y una recuperación más rápida de su crecimiento. El aumento de la liquidez en USA, el mantenimiento de una tasa de interés oficial casi nula y el temor a una deflación, explican la bajada del dólar en los mercados. Japón y Suiza han intervenido en los mercados de divisas para debilitar sus monedas, ciertamente con poco éxito. China, cuya moneda está subvalorada, se niega a presionarla al alza en el corto plazo, por sus efectos "catastróficos" sobre su economía... y sobre la economía mundial.

- La UEM no ha actuado "todavía" en el mismo sentido.

Todo hace temer que se inicie una guerra de divisas para ganar mercado, lo cual es imposible por definición, ya que las depreciaciones se producen frente a otras monedas, por lo que unos ganan y otros pierden; lo más probable es que estas practicas perjudicarían a todos ya que llevarían a un nuevo proteccionismo, poniendo en peligro la recuperación. Organismos internacionales (FMI, el G-20...) han visto con preocupación esta escalada monetaria pero no han sido capaces de reformar unos mercados que funcionan mal. Estos cambios de las cotizaciones, sobre todo del dólar, pueden, probablemente, afectar a otros mercados; así se teme que se produzcan nuevas "burbujas" de los precios del petróleo o de otras materias primas.

Esta es la última "guerra" cuyo final ignoramos. A la hora de cerrar este editorial, la Reserva Federal ha decidido de forma unilateral unas medidas monetarias de 
carácter expansivo que han debilitado el dólar y fortalecido el euro. Esta política estadounidense ha creado un malestar en otros países (emergente, del área euro, etc.) que tendrán más problemas para exportar. La respuesta del BCE ha sido sorprendente: mantiene su propuesta de terminar con la política de inyección de liquidez $y$, en palabras de su presidente, no se debe considerar que la política de Estados Unidos se deba interpretar como una decisión dirigida a debilitar el dólar.

Es claro que este "marco" si se mantiene en el futuro, llevaría a la temida guerra de divisas. Desde un punto de vista global, es indispensable una coordinación de las políticas cambiarias (la Reserva Federal debe dar ejemplo en este sentido). Por parte de la UEM, no se puede mantener una política "pasiva"; en ausencia de dicha coordinación, la UEM debe responder frenando la elevación de la cotización del euro. Teniendo en cuenta que el BCE no tiene competencias en este sentido, deben ser los órganos comunitarios los que aprueben esta política ¿̇será posible el acuerdo?

La reciente reunión del G-20, celebrada en noviembre, no ha acordado ninguna iniciativa sobre los mercados de divisas. El resultado del encuentro ha sido decepcionante; sólo algunos contactos bilaterales pueden ofrecer alguna esperanza de que se puedan lograr mejoras.

\section{A modo de conclusión y valoración}

\section{I. Lo que falta para que la zona del euro sea un área monetaria óptima}

La teoría ha expuesto de forma reiterada las condiciones que debe reunir un espacio para que se pueda considerar como un área monetaria óptima ${ }^{7}$ :

1. Movilidad de los factores de producción.

2. Diversificación sectorial del producto nacional de cada país o región y de sus exportaciones.

\footnotetext{
${ }^{7}$ La exposición de la teoría del área monetaria óptima nos alejaría en exceso de los objetivos de este escrito, por lo que nos limitamos a recordar que estas condiciones pueden asegurar que, ante un "shock" de demanda, o bien los efectos serán análogos en todos los países que constituyen el área, o bien el ajuste será rápido y los desequilibrios no serán excesivamente graves.
} 
3. Homogeneidad del marco de la política económica y del comportamiento de los consumidores.

Para que una unión monetaria presente un saldo positivo, será necesario, por tanto, que en el espacio correspondiente se cumplan estas tres condiciones. En otros términos: en cada uno de los países y también entre ellos, deben aparecer las tres características anteriores. Vamos a analizarlas desde el punto de vista europeo.

La movilidad de capitales en la Unión Europea y en cada uno de los países miembros es una realidad desde la creación del mercado único, que ha alcanzado ya a todos los Estados. El proceso conjunto de unión económica y de unión monetaria viene justificado por esta exigencia de la movilidad de los factores ${ }^{8}$. La creación de un mercado único de capitales, unido a unas relaciones de clientela de carácter secular, y a la existencia de una estructura de los respectivos sistemas de crédito de alcance nacional, determina que la movilidad del capital fuese todavía algo limitada; sin embargo, la rapidez con que se han ido produciendo ciertos cambios, en el sentido de una ampliación de los mercados financieros nacionales hacia un espacio europeo, hace pensar que la movilidad de capitales es ya una realidad plena.

La normativa comunitaria ha puesto, también, las bases para que sea posible la movilidad del factor trabajo en la Unión, tal como sucedía en cada uno de los países. En este aspecto, las costumbres, que parten de tradiciones históricas, las barreras idiomáticas y culturales, hacen muy difícil que la movilidad de los trabajadores se cumpla en la actualidad. El equilibrio de rentas que es necesario en un área monetaria, difícilmente se alcanzará en Europa mediante movimientos del factor trabajo, al menos en un futuro cercano.

Una diversificación profunda, sobre todo de tipo sectorial, del producto nacional de los países comunitarios, significaría una complementariedad de las respectivas producciones, que a su vez permitiría una alta cifra de intercambios comerciales. Esta condición, por tanto, aseguraría la posibilidad de obtener con facilidad un equilibrio económico en todo el espacio monetario lo que no sería posible en unas economías con producciones sustitutivas, en las que el equilibrio se tendría que alcanzar mediante lentas y costosas variaciones de la renta y del producto nacional. En Europa se podría considerar que esta condición se cumple, de forma

${ }^{8}$ Hay precedentes de procesos de integración económica que no han ido unidos a una unión monetaria. En la propia UE, tanto el Mercado Común como el actual mercado único han coexistido con la diversidad monetaria. Sin embargo. es dudoso que una unión económica plena pudiera existir sin unión monetaria: las «fronteras» monetarias impedirían que se pudiese alcanzar una unidad en lo económico. 
suficiente, a la vista del elevado volumen de intercambios comunitarios, lo cual es un reflejo de la gran diversidad sectorial de la producción de los países de la Unión. No hay que olvidar, sin embargo, que las diferencias no sólo tienen un carácter sectorial, sino que también alcanzan a los procedimientos de producción y a la incorporación de innovaciones técnicas. La unión económica y la monetaria ha exigido importantes y difíciles ajustes y mayores retrasos de las regiones menos desarrolladas?

La homogeneidad de las políticas económicas debería determinar unos niveles cercanos de inflación y del tipo de interés entre los distintos espacios, contribuyendo de esta forma al equilibrio económico en todo el ámbito de la moneda única. En la realidad el equilibrio de los tipos de interés se ha logrado, pero no así el de los niveles de precios. En la misma línea, la homogeneidad del comportamiento de los consumidores ha hecho posible que los impulsos de la política económica se transmitiesen en la misma forma y, aproximadamente, en el mismo período de tiempo. Con respecto a esta condición, la diversidad en los países de la UEM era muy elevada. Por ello, fueron adoptadas dos decisiones con el fin de armonizar las políticas económicas de los países miembros: a) la autonomía de los bancos centrales y la prohibición de que el banco emisor financiase el déficit público; y b) la obligación de que los Estados presentasen unos programas de política económica a medio plazo que debían ser discutidos y aprobados por el consejo de ministros de la UEM. Estas normas asegurarían que la política económica de los países miembros siguiese una línea común, pero no hay que olvidar, que la existencia de importantes diferencias de comportamiento de los agentes económicos de los distintos países puede determinar que los mecanismos de transmisión de los impulsos de la política económica funcionen de forma muy diversa en cada uno de los miembros.

Puesto que existían diferencias sustanciales de situación económica entre los distintos países antes de la unión monetaria, se fijaron los criterios de convergencia, que hemos expuesto anteriormente, como condición previa para incorporarse a la UEM. Esta decisión fue oportuna, pero sólo asegura que los países que se incorporen al euro cumplan unas condiciones mínimas, pero evidentemente el funcionamiento adecuado de la Unión requiere que el conjunto de los países sean un área monetaria óptima, para lo cual es necesario el cumplimiento de las condiciones indicadas en los párrafos anteriores.

\footnotetext{
9 Estas circunstancias explican la creación del Fondo de cohesión para paliar los costes de la unión monetaria en los países menos avanzados.
} 
¿Qué pasó para que fallaran estos supuestos previos?:

1. Los países debían estar sometidos a una disciplina fiscal, de forma que se tuviesen un déficit superior a lo previsto o el porcentaje de deuda pública sobre el PNB superase también un cierto nivel serían sometidos a una política comunitaria penalizadora: sin embargo, la UE toleró incumplimientos, incluso, o precisamente, de los grandes países, Alemania y Francia, por ejemplo.

2. Grecia, como ya hemos visto, falseó sus cuentas públicas, dando lugar a un "castigo" de los mercados que se contagió a otros países.

3. Las diferencias sustanciales de las distintas economías fueron evidenciadas por la crisis económica, creando una UEM a dos velocidades.

4. Se olvidó, quizás, que la medida de la deuda exterior incluye también la deuda privada y no sólo la pública; algún país, tal como España, tiene un nivel de deuda pública moderado, aunque creciente, pero el conjunto de su deuda mantiene un nivel excesivo.

5. La lentitud de respuesta de la UE a los problemas de deuda y el limitado alcance de su política es un problema, quizás el más importante, que explica la crisis de la UEM. Sin una política económica común difícilmente puede funcionar una unión monetaria y esto quizás no se comprendió claramente cuando se inició el proceso de creación del euro.

\subsection{El futuro de la UEM}

Hacer previsiones económicas es siempre arriesgado, especialmente en momentos tan confusos y convulsos como los actuales. Nos limitaremos, por tanto, a realizar unas previsiones sobre el futuro de la eurozona en varios escenarios distintos.

$1^{\circ}$ La política monetaria sería la "única" política común del área y la "guerra de divisas" no llegaría a estallar. En este caso, la recuperación dependería de las políticas de los Estados por lo que probablemente se mantendría la Europa de dos velocidades; la insistencia del gobierno alemán en fijar como objetivo casi único la estabilidad presupuestaria no ayudaría demasiado a los países del área con más dificultades. Los mercados continuarían penalizando a las economías más endeudadas (Irlanda, Portugal, quizás Grecia, de nuevo); el encarecimiento de estas emisiones de deuda pública haría todavía más difícil la recuperación de sus 
economías, manteniendo por lo tanto las dos velocidades. No se descarta totalmente que alguna moneda tuviera que salir del euro, aunque esto lo consideramos poco probable; sí es posible, no obstante, que algún país necesite la ayuda del fondo europeo creado recientemente. Los últimos datos conocidos muestran que la UE va ligeramente mejor de lo previsto, pero esta imagen oculta las diferencias internas existente en el área y que hemos destacado en este escenario.

$2^{\circ}$ De nuevo, consideramos la política monetaria como la "única" política económica común posible en la UE, mientras que consideramos que la llamada "guerra de divisas" alcanzaría la máxima virulencia. Este escenario vendría determinado por la globalización; la UE sólo podría responder a la situación pero carece de "poder" para modificarla. Si el BCE permitiese la apreciación del euro, se produciría un déficit exterior de la eurozona y unos efectos sobre el nivel de precios idénticos a los de una política monetaria antiinflacionista; quizás sería posible una moderada subida del tipo de interés oficial sin perjudicar excesivamente el crecimiento; pero es poco creíble que las autoridades europeas no respondiesen a la política cambiaria de otros países sin intentar debilitar el euro; como hemos comentado ya, esta peligrosa política podría llevar a una nueva recesión; insistimos en que la UE sólo puede responder ante las condiciones de este escenario pero no modificarlo.

$3^{\circ}$ La UE establecería una política económica común ¿̇sólo para la UEM? Realmente esta política exige una coordinación de las políticas fiscales (tanto de gastos como de ingresos) de los Estados miembros, pero ello parece una utopía en estos momentos. Anteriormente, hemos visto decisiones comunitarias que van en la línea de una política económica común: a) creación de un fondo para atender posibles crisis de liquidez (o de solvencia) de algún país; b) un examen, previo a su aprobación, de la propuesta de presupuesto público de cada uno de los Estados miembros, a la vista de la cual, la UE podría proponer modificaciones, no vinculantes; c) penalización rigurosa de los países que superaran los límites del déficit y de deuda públicos; los apartados " $b$ " y " $c$ " están siendo objeto de deliberaciones actualmente, por lo que sus detalles concretos todavía no se han aprobado. Por supuesto, este escenario puede ir unido a algunas de las situaciones ya citadas: a) ataque de los mercados financieros contra alguna economía; b) "guerra" de divisas, etc., que podrían complicar la política de la UE. Podemos, sin embargo, sostener que sólo en un escenario como éste, puede mantenerse la UEM. Hace falta una política económica común clara y decidida; si continúan las indecisiones y los retrasos, la UE, y en concreto la UEM, irá perdiendo importancia en la economía mundial. 
La reciente cumbre europea de 28 de octubre muestra que estamos aún bastante lejos de esa política económica común. ¿2Hay que hacer una reforma (¿̇mayor, más limitada?) del Tratado de Lisboa, para una nueva gobernanza económica de Europa (y del euro)? ¿ ¿o hay que recuperar, si es posible, el gradualismo europeo, la política de pequeños pasos, adelante-atrás?

\subsection{Consideraciones finales}

En los apartados anteriores hemos analizado el concepto de UEM, su funcionamiento y su comportamiento durante la crisis económica y financiera, todo ello desde un punto de vista técnico, económico y financiero, principalmente. En este apartado final queremos hacer una valoración de la moneda única, deteniéndonos primero en el caso español y después en el conjunto del área del euro.

En el caso español, si no hubiéramos estado dentro de la UEM ¿̇nos hubiera ido mejor o peor? El euro, ì ha mitigado la crisis o la ha agravado? Para responder a esta pregunta, debemos tener en cuenta que en la actualidad se escuchan muchas voces, especialmente desde el punto de vista de España y de otros países afectados por la crisis de la deuda, que critican la pertenencia de algunas economías a la UEM. Sin duda, si España, por ejemplo, no se hubiera incorporado a la zona euro, es decir, si no hubiera renunciado a los instrumentos de política monetaria, hubiera podido desenvolverse mejor ante la crisis financiera, al menos desde un punto de vista estrictamente monetario y de manejo del déficit público. En particular, obviamente, hubiera podido devaluar su moneda. Pero esa consideración debe ser completada con otras.

Por una parte, la historia de las devaluaciones llevadas a cabo por España en las últimas décadas (en cuyo análisis no podemos entrar aquí) demuestra que son solamente un elemento, y no el principal, de los cambios estructurales experimentados por nuestro país. Sin duda, esos cambios han sido insuficientes, pero la economía española ha dado pasos de gigante desde su ingreso en 1986 en la Comunidad Económica Europea.

En segundo lugar, es muy fácil decir hoy qué ventajas se han perdido por permanecer a la zona euro; pero es muy difícil valorar lo que podría llamarse "el costo del no-euro" (haciendo un símil con los famosos análisis de los 80 acerca del coste de "la no-Europa", para cuantificar lo que se dejaba de ganar por la inexistencia de un mercado único). No haber entrado en la zona euro, hubiera tenido grandes costes, tanto en el terreno económico y comercial como en el más 
estrictamente político. El esfuerzo por superar el examen de convergencia creó una nueva cultura en la política económica española: los actores se acostumbraron al rigor presupuestario, a la disciplina de precios, a la estabilidad como marco obligado para el crecimiento económico.

Por otro lado, achacar-como lo hace Krugman- el crecimiento económico español de los últimos 25 años sólo a la burbuja inmobiliaria es una simplificación abusiva. La economía española se ha visto beneficiado por otros muchos efectos positivos de su pertenencia a la UE, en general, y a la zona euro en particular.

En términos generales, la incorporación a Europa, al núcleo duro de Europa que incluye la pertenencia al euro, ha acarreado muchos otros efectos benéficos, no solo ni principalmente de índole económica. Los cambios espectaculares inducidos en la sociedad española por la incorporación a Europa, después de oscuras décadas de dictadura, incluyen la adaptación al modelo político democrático europeo, la integración comercial más plena con los países europeos, la modernización espectacular de nuestra legislación, los avances impresionantes en las infraestructuras con un considerable apoyo de los fondos europeos, etc.

¿Cuánto de todo eso se hubiera visto comprometido sin el ingreso en la Unión Monetaria? Nuestro país hubiera quedado en la periferia de la UE, como un país de segunda categoría, mucho menos atractivo para las inversiones extranjeras con una moneda desprestigiada (la peseta no es la libra esterlina...), unos intercambios comerciales sujetos a los vaivenes del tipo de cambio de la peseta, etc.

El profesor Luis Ángel Rojo, antiguo gobernador del Banco de España, confirma la "bondad" de que España se encuentre en la zona euro pues opina que esta circunstancia ha determinado en el caso español incrementos del producto, de los puestos de trabajo y del bienestar, y que ha ayudado a resolver ciertos problemas y a prevenir la aparición de otros ${ }^{10}$.

Desde un punto de vista más general, hay que recordar que Krugman afirma que los problemas vienen porque los países pertenecientes a la UEM han renunciado a su propia soberanía. Sin embargo, la opinión de Rojo en el texto citado es claramente favorable: para dar valor a sus opiniones, indica que algunos países

10 Véase la intervención del profesor Rojo dentro de la obra reseñada en este mismo número: J. F. JIMENO (ed.) (2010) Spain and the euro The first ten years, Madrid, Banco de España. Por otra parte, el número 41 de los Cuadernos Europeos de Deusto está dedicado también a los diez años del euro; su lectura completa en muchos aspectos el texto de este editorial. 
que no pertenecen a la UEM hubieran preferido estar en el área del euro durante la crisis actual; considera sin embargo que la moneda única no es una panacea; citando por ejemplo que los agentes económicos se han adaptado gradualmente a la situación de estabilidad, si bien ello hace necesario adoptar modelos de conducta consistentes con una baja inflación y cambios en los mercados y en las instituciones. En resumen, Rojo afirma que la moneda única exige una utilización más intensa de la política fiscal y de la políica de oferta, ya que son los únicos instrumentos que tienen los gobiernos nacionales.

No es ésta nuestra única duda. Así, por ejemplo, nos planteamos si el tratamiento autónomo del tema del euro y de la política monetaria de la UE guarda coherencia con la necesidad de imbricar las lógicas económicas predominantes con la "lógica sistémica de la fraternidad"11. También nos preguntamos si no parece excesiva la pretensión de autonomía económica que reclaman los constructores de la Unión Europea cuando mantienen a distancia y en el ostracismo todo discurso, argumentación o razón que provenga del universo de la Política, el Derecho, la Ética, la sociedad civil, los derechos sociales, el acervo cultural y real del Estado social y democrático. Por otra parte, aun estando de acuerdo con la idea de la construcción de Europa, ¿̇no corremos el riesgo de caer en la ingenuidad apoyando acríticamente esta Unión Europea? ¿ ¿Es verdaderamente más social y más justa ly, por ello, más cristiana) la Europa-Mercado regida política y socialmente por el Euro y lo que éste supone en la realidad histórica actual?

Y además de lo anterior, como hemos apuntado en párrafos previos, la UEM tiene problemas que hay que intentar resolver ${ }^{12}$. Así, creemos que hace falta una política económica común clara y decidida; si continúan las indecisiones y los retrasos, la UE, y en concreto la UEM, irá perdiendo importancia en la economía mundial, pero ante esto cabe plantearse: ¿̇la UEM es viable con una mayor coordinación de las políticas económicas? o jes necesario avanzar hacia una única política económica que sólo sería sustentable desde una unión política?. Igualmente, es preciso dar pasos de lo económico a lo político (la zona débil de la construcción europea) y fortalecer los liderazgos europeos; de hecho los últimos meses están marcando el liderazgo de Alemania, aunque quizás priorizando sus propios intereses. Nos preguntamos si un consenso básico franco-alemán, ¿̇sería positivo

\footnotetext{
${ }^{11} \mathrm{Cfr}$. "Ser hermanos más allá de la globalización. El desarrollo humano integral en Caritas in Veritate" Revista de Fomento Social, núm. 258, pp. 201-202

${ }^{12}$ El propio presidente de la Unión Europea, Herman Van Rompuy, alertó sobre la extensión del nacionalismo en la Unión Europea, llegando a afirmar que si el euro cae, cae Europa.
} 
para la UEM o por el contrario podría acentuar los problemas actuales? Por último, creemos que hay que reactivar el consenso europeo buscando un consenso cívico participativo $^{13}$.

Desde nuestras convicciones europeístas reiteradamente expuestas en esta revista, creemos que siempre que haya voluntad política de avanzar hacia una política económica común, se ha abierto ahora con esta "crisis" una segunda oportunidad para el euro.

\section{NOTA}

Los acontecimientos en los mercados, sobre todo en los financieros, se producen a una velocidad tal que en poco tiempo los análisis quedan anticuados. Cuando las decisiones dependen de la Unión Europea, los cambios son más lentos, "las cosas de palacio..."

Desde que se terminó la redacción de este editorial ha habido pocos cambios importantes. En el terreno de la política de la UME, y en general de la UE, lo principal ha sido el haber dado carácter permanente al Fondo, que alcanza de esta forma una mayor estabilidad; también se ha emprendido un fortalecimiento del gobierno económico de la UE, sólo incipiente, mientras que se han rechazado otras propuestas, principalmente por parte del gobierno alemán, tales como la emisión de bonos europeos.

En relación con los mercados, habría que señalar la bajada de la cotización del euro (quizás sería más exacto hablar de volatilidad de la moneda europea), si bien esto no ha sido resultado de una política comunitaria. Un fenómeno que podrá ser importante en el futuro es la compra de bonos soberanos europeos por parte de China y en menor medida por Brasil. Es difícil prever en estos momentos el comportamiento de los mercados, así hemos visto que las cámaras de compensación, a las que hemos aludido, no han resuelto el problema de falta de financiación; en otro campo, la deuda alemana (y también la de USA) está demasiado cara por lo que ya resulta complicada la emisión de los títulos de esté país.

Por último, la incorporación de la moneda de Estonia al euro ha sido un elemento positivo para la UME, aunque quizás no vaya mucho más allá de una cuestión de imagen.

Las incógnitas en estos momentos siguen siendo numerosas. Ya veremos...

${ }^{13}$ Gonź́lEZ, F. (2010), Mi idea de Europa, Barcelona, RBA 